\title{
Review: development of performance-based fire design for cold-formed steel
}

\author{
Jean C Batista Abreu*, Luiz M C Vieira Jr², Metwally H Abu-Hamd³ and Benjamin W Schafer ${ }^{4}$
}

\begin{abstract}
Performance-based fire design for cold-formed steel systems is in its infancy. This paper brings together existing research on cold-formed steel materials, members, and assemblages at elevated temperatures; and complementary analysis and design methods necessary for the development of analysis-based design for cold-formed steel systems under fire. Cold-formed steel systems have become popular in building construction as both load-bearing and non-load-bearing elements, primarily due to their high strength-to-weight ratio and ease of construction. Consequently, design specifications, and structural analysis tools have rapidly evolved to facilitate engineering design of these complex thin-walled members. However, in fires the performance of cold-formed steel systems are assured by prescriptive detailing and standardized testing. Today, engineering knowledge is rapidly advancing, providing the opportunity to contemplate analysis-based design as an enabling tool for general performance-based fire engineering of cold-formed steel systems. The review provided here includes experimental results on mechanical and thermal properties of cold-formed steel and temperature dependent constitutive relations, subsystem testing and computational simulations, and analysis models and exploratory methods for fire design, i.e., the building blocks towards performance-based fire design for cold-formed steel systems.
\end{abstract}

Keywords: Cold-formed steel; Fire resistance; Retention factor; Prescriptive fire design; Performance-based fire design; Thermo-mechanical model; Structural stability

\section{Introduction}

Cold-formed steel (CFS) members are manufactured from cold bent sheet steel, approximately from $0.5 \mathrm{~mm}$ to $3.0 \mathrm{~mm}$ thick. The most common members are channels (tracks) and lipped channels (studs and joists). CFS stud and track are used extensively in buildings as the framing for interior partition walls, exterior curtain walls, and more recently as the complete load-bearing system (Allen 2004, Schafer 2011). CFS interior partition walls are framed with studs, have track at top and bottom, and are then sheathed (most commonly) with gypsum wallboard (s). In a fire, partition walls serve as primary barriers to maintain building integrity, and avoid the spread of fire between compartments (rooms). In the United States, the assemblies are required to be "fire-rated" (IBC 2012) based on their ability to withstand a standardized "fire" test (ASTM 2012). The fire-resistance rating is expressed by

\footnotetext{
* Correspondence: jbatist1@jhu.edu

${ }^{1}$ Department of Civil Engineering, Johns Hopkins University, Baltimore, MD, USA

Full list of author information is available at the end of the article
}

the number of hours that the assembly can maintain its integrity while containing gases and excessive temperature increases out of the fire compartment. A large number of assemblages have been tested, and industry has assembled catalogs of the prescriptive details that can provide a given fire rating (CFSEI 2012). These prescriptive solutions are critical to current design and represent an important review of the state of the art in their own right; however, the focus here is on enabling performance-based fire design, not additional prescriptive solutions.

To date, fire design for load-bearing CFS systems (where the complete structural system is framed from CFS members) has followed the same test-based, prescriptive detaildriven approach that has been previously established for interior partition walls. However, given the wide variety of possible members and details the prescriptive approach has several drawbacks, as discussed in The case for performance-based fire design of cold-formed steel systems section. In addition, hot-rolled steel has demonstrated the possibilities and advantages of enabling performance-based fire design (e.g. AISC 2010). Further, recent research has taken 
the first steps towards performance-based design for establishing the fire resistance of CFS structures, including temperature dependence of the material (mechanical and thermal) behavior, thermo-mechanical response of members and sub-systems, and temperature dependence of member strength predictions. This state-of-theart review discusses current research and recent findings on the fire performance of CFS.

\section{Fire demands and heat transfer analysis of CFS systems}

Fundamental to determination of the fire resistance is establishing the fire demand and then propagating that demand to the underlying members. Ideally, performancebased fire design brings the demand (fire modeling), propagation (heat transfer), and capacity (strength at elevated temperatures) all into the realm of analysis. In such a situation, the complete system may be designed for the desired fire performance with interactions between demand, propagation, and capacity fully included through analysis. Although the focus of this review is on capacity, demand and heat transfer is briefly reviewed here to establish the conditions under which the capacity is evaluated.

\section{Fire demand}

One of the first formal attempts to account for fire action on building structures emerged in 1918, when the ASTM standardized a time-temperature relationship (called the fire curve) to consistently evaluate the fire resistance of buildings. The fire curve was intended to represent a worst-case expected fire scenario, based on empirical data from timber construction (ASCE 2009). Similar time-temperature relationships have been implemented internationally. Typically, the fire curve is only weakly related to the actual time-temperature curve for a fire in a modern building. However, standard fire curves provide a consistent benchmark and their use is so pervasive that generally they are regarded as fire demand regardless of the specifics.

Parametric fire curves represent a modest generalization of the fire curve approach (CEN 2002). Typically, it is assumed that a building compartment is subjected to a uniform temperature distribution that follows the parametric fire curve. The curves include factors related to the compartment dimensions, size and number of openings, and amount of combustible materials and result in a unique intensity and duration for the fire. In general, parametric fire curves include a nonlinear heating phase followed by a linear cooling phase, while the standard fire is represented by an increasing curve (Figure 1). A further evolution of parametric fire curves is the use of "zone models" (Quintiere 1989). In zone models the compartment is divided into multiple regions, each with its own uniform temperature distribution following a parameterized fire curve. Amongst other details, these models account for

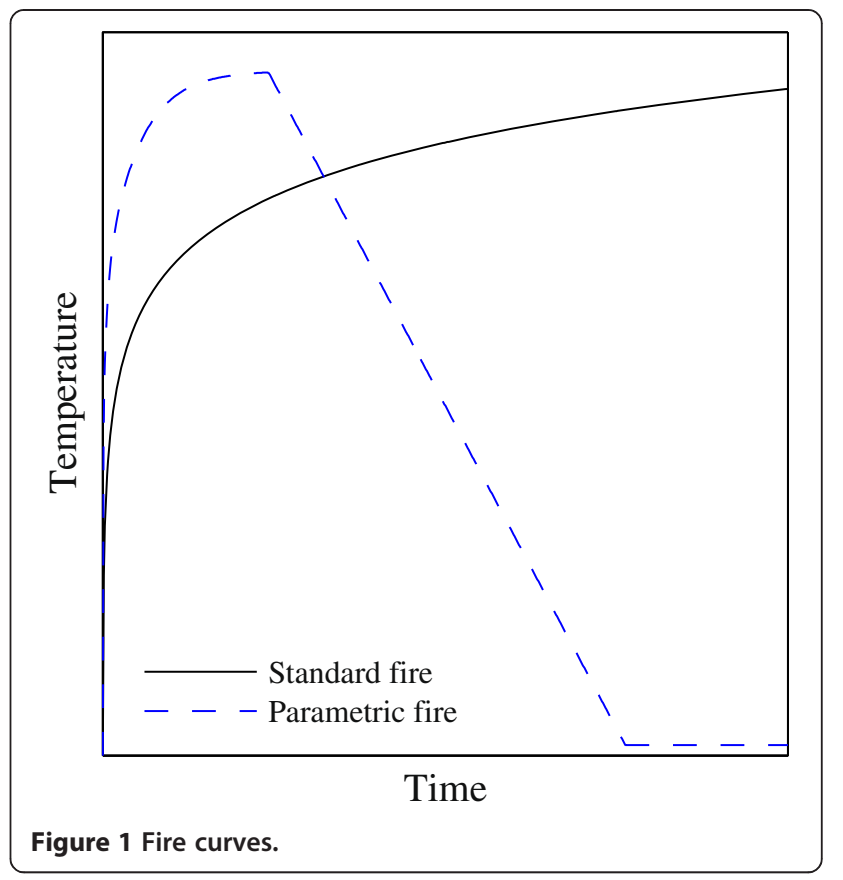

the fact that higher temperatures are observed in the upper zone of the compartment.

The most sophisticated simulations adhere to computational fluid dynamics (CFD) and at some level attempt to model actual fire dynamics. These models are used to predict the development of fire in a building structure (including fully three-dimensional models), incorporating flames and smoke propagation. CFD simulations are complex, require a high level of expertise, relatively long computation times, and can be challenging to calibrate. Nonetheless, true performance-based design of fires relies on the long-term potential of this approach. Multiple software solutions are in current use, including PHOENICS (Spalding 1978), FDS (McGrattan et al. 2002), SMARTFIRE (Ewer et al. 2008) and SOFIE (Rubini 2006).

\section{Heat transfer}

Once the thermal fire demands are established, the next step is to propagate these demands to the structure itself through heat transfer analysis. For an actual fire, temperature distributions on CFS members are nonuniform and vary through the cross-sections and along the length. Fully three-dimensional heat transfer models of CFS assemblages are possible (Santos et al. 2013), but not common. Instead, simplified one-dimensional heat transfer models are generally used to estimate the temperature history across assemblages (walls, floors, etc.) subjected to fire action on one side (Sultan 1996; Alfawakhiri 2001; Keerthan and Mahendran 2013; Chen et al. 2013). These models require accurate thermal models of all materials in the assemblage. Generally, the heat conduction through and radiation from the steel 
studs are ignored, and shrinkage, cracking and ablation processes of the gypsum boards are not explicitly modeled, although their effects are considered by modifying material thermal conductivity and specific heat. Also, moisture migration and hot air flow are ignored, thus thermal gradients along the length of the assemblage (i.e., height of the wall) are ignored. It is also common to make the simplifying assumption that the temperature varies linearly throughout the web of the CFS member in the assemblage, while the temperature of the flanges and lips are constant (Shahbazian and Wang 2013). See Performance of Walls section for further discussion of modeling heat transfer in CFS assemblages.

\section{Cold-formed steel material at elevated temperatures}

During a fire, the temperature of structural members increases and, subsequently, material properties change. Mechanical properties of steel such as the elastic modulus, yield stress, and ultimate stress degrade with increasing temperature, thus steel members lose strength and stiffness under increasing temperature. Thermal properties also vary with temperature, e.g. steel incurs phase transformations under highly elevated temperatures that significantly alter thermal response. Quantification of the temperature dependence of thermal and mechanical properties of sheet steel is a fundamental building block for predicting the response of CFS under fire.

\section{Mechanical properties}

Several research groups have studied mechanical properties of sheet steel at elevated temperatures (Lee et al. 2003; Chen and Young 2007; Ranawaka and Mahendran 2009a; Kankanamge and Mahendran 2011; Chen and Ye 2012). In general, tested specimens range from $0.50 \mathrm{~mm}$ [0.0188 in.] to $2.00 \mathrm{~mm}$ [0.0713 in.] thick, with yield strengths from $250 \mathrm{MPa}$ [36 ksi] to $550 \mathrm{MPa}$ [80 ksi] at ambient temperature. Typically, the experimental results are presented as retention factors, which are ratios of a material property at elevated temperature with respect to the same property at ambient conditions. Retention factors vary among research efforts (Figure 2) and the proposed prediction equations differ as well (Figure 3). Differences are mainly attributed to the test method, strain rate, heating rate, material grade, and the criteria used to determine the yield stress - as discussed further below.

Tensile tests at elevated temperatures are traditionally conducted by either steady-state, or transient-state testing. During steady-state tests, the temperature on the specimen is increased to a given level and then, after the temperature becomes stable, external load is gradually applied until failure occurs. In contrast, during transient-state tests, the load is statically applied to the specimen, and the temperature is gradually increased until a failure criterion is met. Results are dependent on

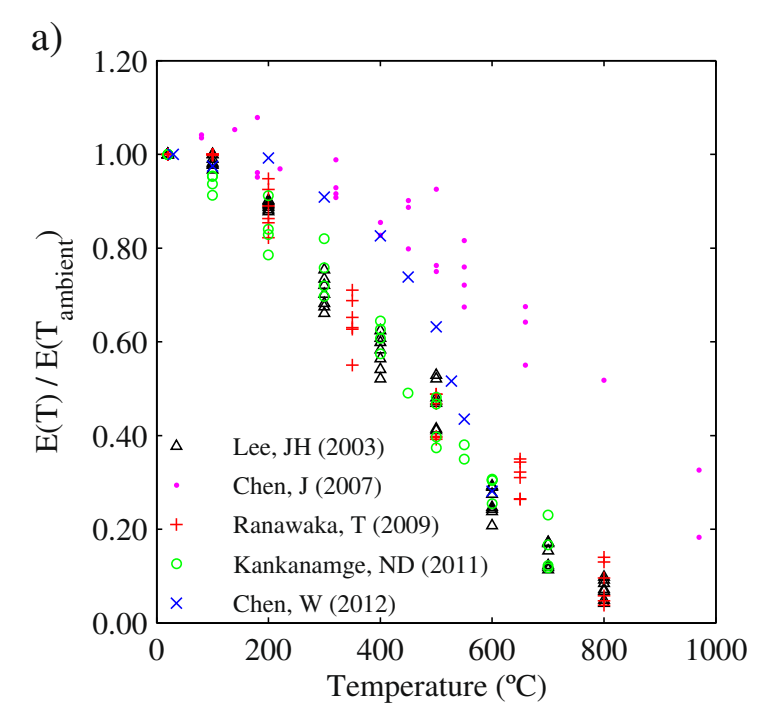

b)

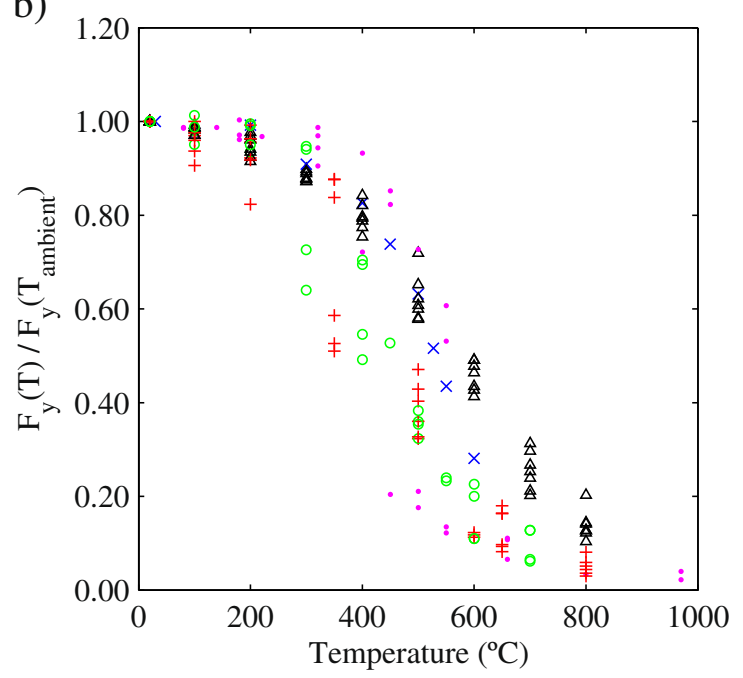

Figure 2 CFS retention factors for the (a) elastic modulus and (b) yield strength from steady-state tests.

the test method. Although the steady-state test is more popular (and generally easier to conduct), the transientstate test is considered more realistic as it is consistent with a member under an applied static load (e.g. a gravity loaded column) undergoing temperature increase, as in a fire (Outinen and Mäkeläinen 1999). In general, transient-state tests show a higher degradation than steadystate tests, e.g. see the retention for Young's modulus in Figure 4-a. Though common, the use of retention factors from steady-state tests may lead to overestimated stiffness and strength (Chen and Ye 2012).

Strain rate, typically not influential for sheet steel at ambient temperatures under common loading or testing rates, does influence the results in strain-controlled steady-state tests at temperature. Figure 2 shows that retention factors obtained using a strain rate of $0.006 \mathrm{~min}^{-1}$ (Chen and 


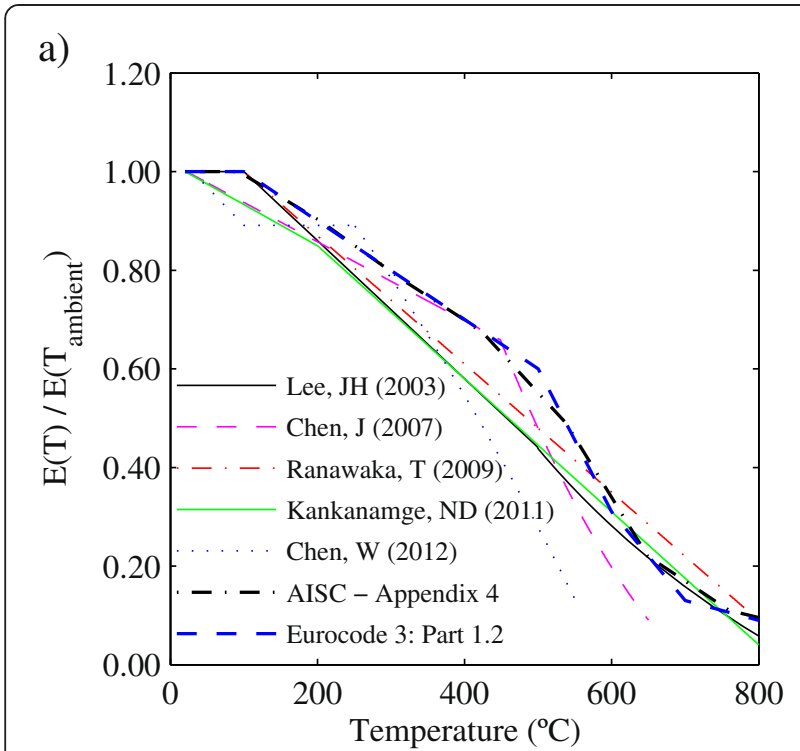

b)

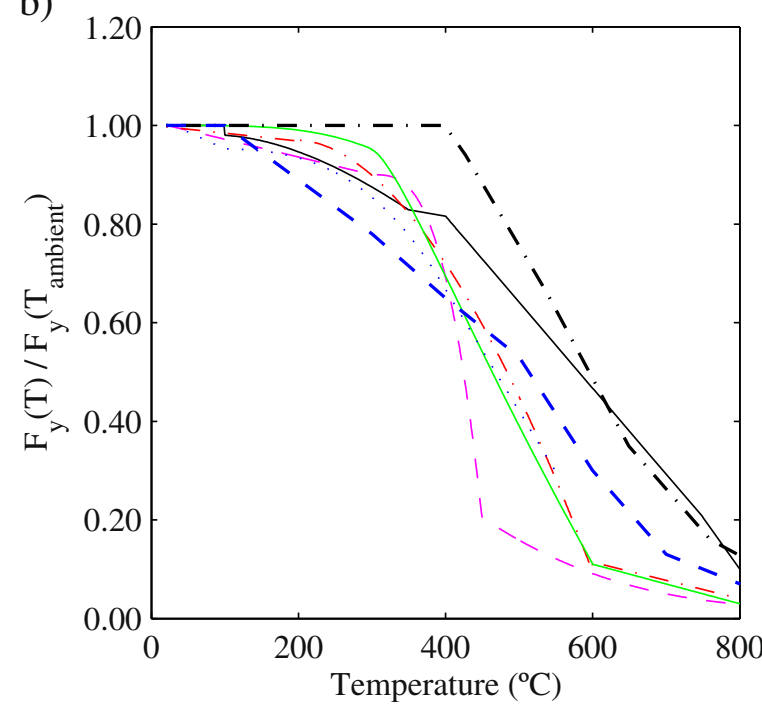

Figure 3 Proposed retention factors for the (a) elastic modulus and (b) yield strength of steel.

Young 2007) are higher than the factors obtained using strain rates at about $0.003 \mathrm{~min}^{-1}$ (Lee et al. 2003; Ranawaka and Mahendran 2009a; Kankanamge and Mahendran 2011; Chen and Ye 2012). In general higher strain rates lead to higher (stiffer) response (Cooke 1988). In addition, retention factors for yield stress based on high strain rates often lead to a yield and ultimate strengths at similar magnitudes (Kankanamge and Mahendran 2011). Thus, some care must be taken to insure strain rate is consistent with expected final use, when establishing retention factors.

High heating rates may also induce high strain rates during the heating process in transient-state tests (Outinen 2006). Expected heating rates for structural steel members

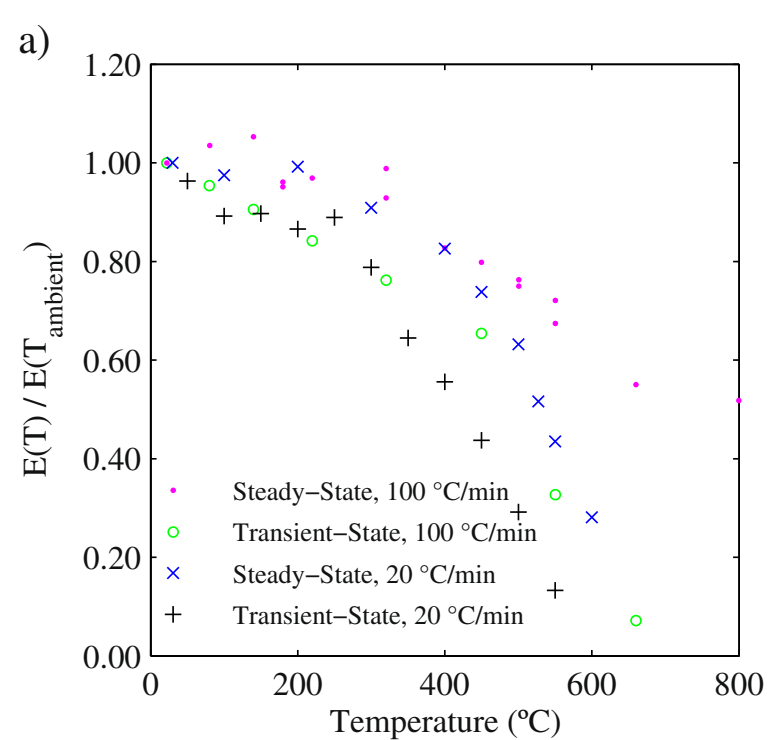

b)

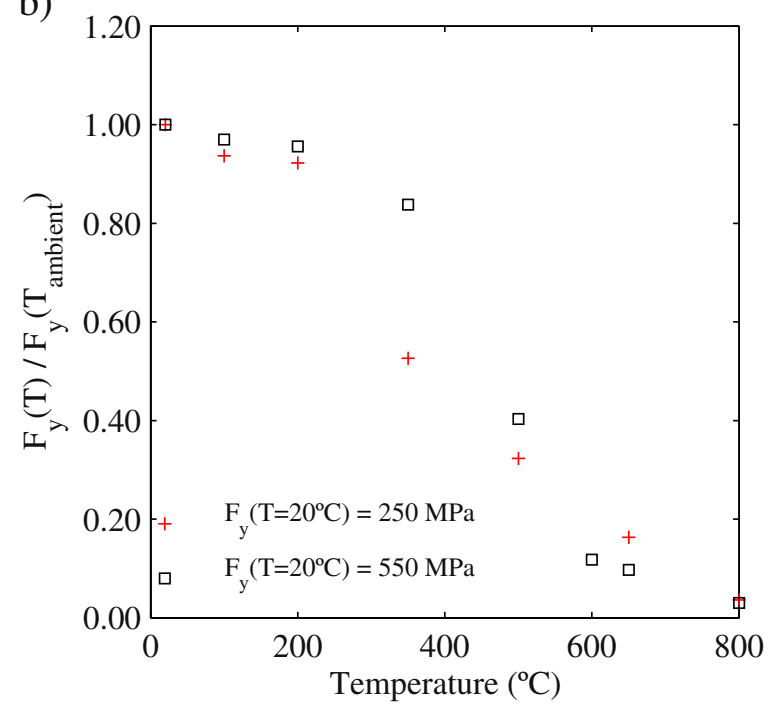

Figure 4 CFS retention factors for the (a) elastic modulus from steady state and transient state tests, and (b) yield strength for different steels.

with 2 hour fire rated protection and unprotected sections are approximately $5.0 \pm 2.0^{\circ} \mathrm{C} / \mathrm{min}$ and $32.5 \pm 7.5^{\circ} \mathrm{C} / \mathrm{min}$, respectively (Kodur et al. 2010). Typically, heating rates adopted in transient-state tests on CFS specimens vary from 10 to $20^{\circ} \mathrm{C} / \mathrm{min}$. These values are not necessarily within the expected range during a fire, or even considered in computational simulations to predict the response of CFS structures. Figure 4a shows that retention factors obtained using a heating rate of $100^{\circ} \mathrm{C} / \mathrm{min}$ (Chen and Young 2007) are higher than the factors obtained using $20^{\circ} \mathrm{C} / \mathrm{min}$ (Chen and Ye 2012). High heating rates result in high-predicted strengths since material damage may be delayed under rapid temperature increases (Bednarek and Kamocka 2006). Also, during tensile tests, the temperature 
is assumed to be uniform in the specimen, so it is important to provide enough time to stabilize the temperature and avoid significant thermal gradients. When the heating rate is high, it is more difficult to accurately monitor the temperature and guarantee a uniform distribution. In addition, heating rate alters the creep effect in sheet steel (Outinen 2006).

It has been posited that differences in chemical composition lead to different retention factors as a function of steel grade (Ranawaka and Mahendran 2009a). Young's modulus shows little dependence on steel grade, but retention factors for yield stress show a more complicated dependence. Researchers report that high strength steel (i.e. $\mathrm{F}_{\mathrm{y}} \sim 550 \mathrm{MPa}$ ) is more efficient than common (low strength) steel grades at about $400^{\circ} \mathrm{C}$ and above (Lee et al. 2003). However, the available experimental data is limited, and mixed. As shown in Figure 4-b, the transition temperatures from high to low retention factors may be different depending on steel grade (Ranawaka and Mahendran 2009a), but overall retention factors for yield stress are similar across grades. Determining yield stress retention factors is itself dependent on strain level, heat level, and the formal method for determining yield stress. The retention factors vary according to the yield point and yield strain definitions. Usually, the yield point is based on the $0.2 \%$ offset strain. However, other offset strains might be adopted to define the yield point. For instance, AISC (2010) provides yield stress retention factors for hot-rolled steel based on $2 \%$ offset strain. In general, the larger the offset strain used to define the yield point, the closer the retention factors for yield and ultimate stresses are.

Usually, temperature-dependent constitutive relations are based on the Ramberg and Osgood (1943) model:

$$
\varepsilon_{T}=f_{T} / E_{T}+k_{T}\left(f_{T} / f_{y \cdot T}\right)^{n_{T}}
$$

Where $\varepsilon_{T}, f_{T}, E_{T}$ and $f_{y . T}$ are the strain, stress, Young's modulus and yield stress at a temperature $\mathrm{T}\left({ }^{\circ} \mathrm{C}\right)$, respectively; and, $k_{T}$ and $n_{T}$ are parameters obtained from regression analysis. The Ramberg-Osgood strength coefficient, $k_{T}$, proposed by Chen and Young (2006a; 2007) and Chen and Ye (2012) is $0.2 \%$. According to temperaturedependent equations proposed by Mahendran and his colleagues, $k_{T}$ ranges from $0.08 \%$ to $0.31 \%$ (Ranawaka and Mahendran 2009a; Kankanamge and Mahendran 2011); however, all cases the $0.2 \%$ offset method was used to compute the yield stress used in RambergOsgood equations. At ambient temperature (around $25^{\circ} \mathrm{C}$ ), typical Ramberg-Osgood hardening coefficients $\left(n_{T}\right.$ ) for cold-formed stainless steels range from 4.5 to 12.2 (Rasmussen 2003). However, ${ }^{n_{T}}$ computed from temperature-dependent equations ranges from 17.2 (Chen and Young 2007) to 57.6 (Ranawaka and Mahendran 2009a) at ambient temperature, for cold-formed carbon steel G550, under steady-state testing conditions. According to proposed equations, $n_{T}$ tends to decrease with increasing temperature, up to $450^{\circ} \mathrm{C}$. Then, up to $800^{\circ} \mathrm{C}$, $n_{T}$ ranges from 4.6 (Chen and Young 2007) to 24.8 (Chen and Ye 2012). Clearly, more work is needed to clarify the correct application of Ramberg-Osgood expressions under temperature for low carbon sheet steels.

Current steel design codes (AISC 2010; CEN 2005) provide retention factors for mechanical properties of steel at elevated temperatures, as shown in Figure 3. General trends for CFS specimens are consistent with the wider database of tested hot-rolled steels, but material and test method dependent scatter exists and, in some cases, particularly around $400^{\circ} \mathrm{C}$, observed reductions of yield stress are far greater in CFS than in the code-based expressions for hot-rolled steel.

The manufacturing process for CFS sections can create significant changes in the material properties, particularly near the corners, in a phenomenon typically referred to as cold work of forming. This additional cold work of forming strength is gradually lost with increasing temperatures (Mäkeläinen and Outinen 1998; Lee et al. 2003), and completely disappears above $500^{\circ} \mathrm{C}$ (SCI 1993). However, CFS maintains its nominal yield strength without cold work of forming after heating and cooling (Outinen and Mäkeläinen 2004).

Other material properties such as density and Poisson's ratio of steel are commonly assumed to be constant (Kaitila 2002). Nevertheless, mass density slightly decreases (Costes 2004) and Poisson's ratio increases (Clark 1953) with increasing temperature (see Figure 5). Prediction equations for the Poisson's ratio of CFS are not available; however, working directly from the available data may be useful to infer other constitutive parameters, such as shear modulus.

Significant limitations exist with the available data. At the most basic level, for use in the United States, the tested CFS does not conform to ASTM A1003 as specified in AISI (2012a). Further, the impact of temperature on residual stresses and strains has seen only limited study (Feng et al. 2003a; Lee et al. 2003). Since the cold-working process influences both explicit design expressions (cold work of forming) and implicit design expressions (the basic column curve) the impact of temperature (potentially similar to annealing) could be influential. The relatively common practice of cold-reducing the steel to a desired thickness has also not seen separate study for its effect on properties under temperature. CFS creep effects and behavior after the cooling phase have been scarcely studied (Outinen 2006). Moreover, unresolved issues at ambient temperature such as the difference in tensile and compressive yield strength in CFS (Karren 1970; Uribe 1969) also become more important as attempts to predict capacity are advanced. 


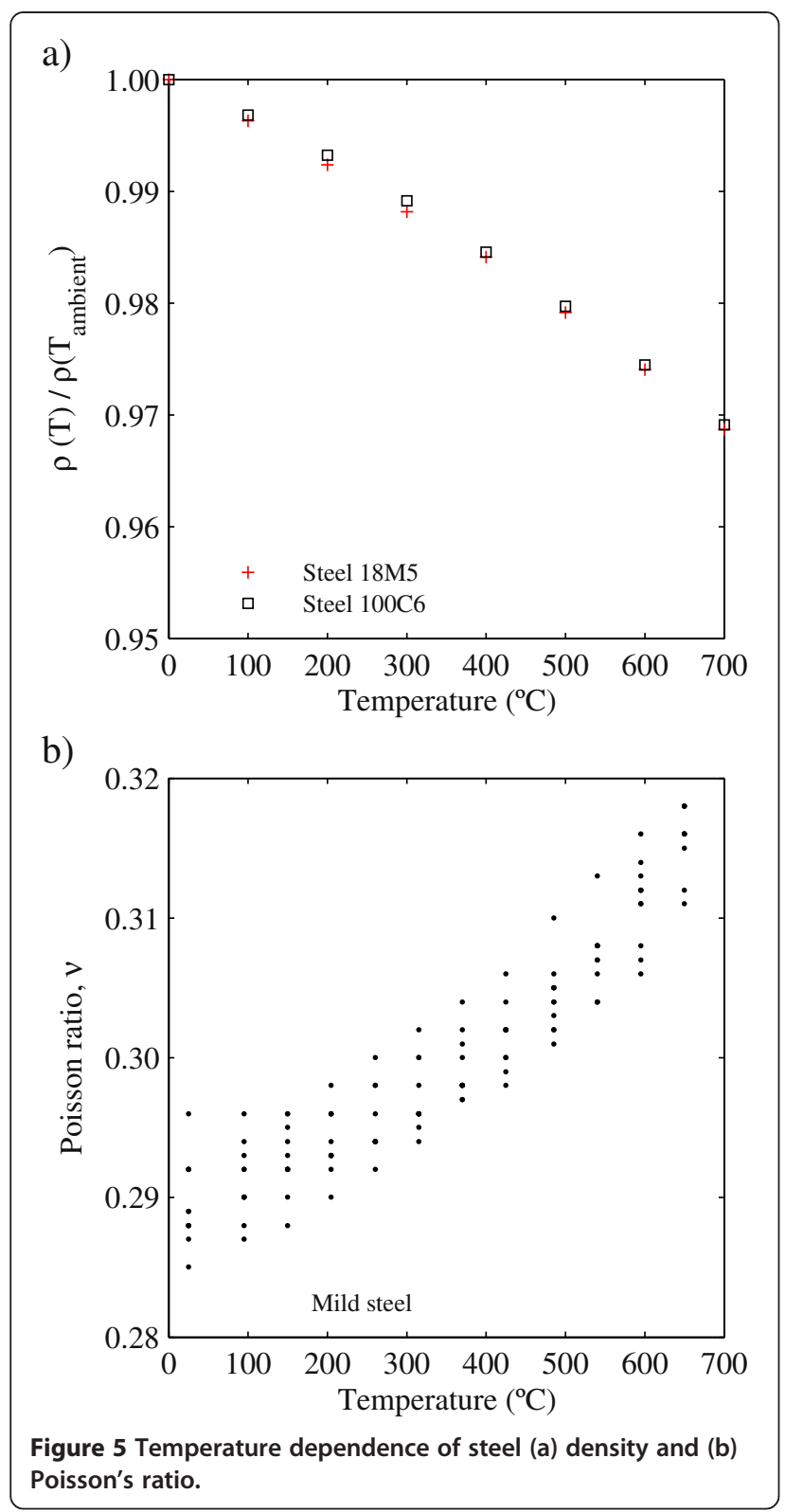

In summary, research needs related to the mechanical properties include determining suitable heat rates that represent realistic fire conditions to study the material response during the heating and decaying phases of fire, and after cooling down. The influence of heat and load (or strain) rates on the mechanical properties at high temperatures needs to be studied, so the advantages and disadvantages of different types of test (i.e. steady-state and transient) are better comprehended. Furthermore, attention should be paid to the chemical composition of specimens tested since the mechanical response seems to differ among different materials, and even for the same material before and after the cold-reducing process. Since mechanical properties at elevated temperatures might depend on the loading conditions, compression tests are also needed for material characterization. Data needs also include the Poisson's ratio, shear modulus, and characteristic stress-strain relations of CFS at elevated temperatures.

\section{Thermal properties}

Thermal properties govern heat transfer and thermal deformations. Though important, they have seen less study than mechanical properties by the structural engineering community. At highly elevated temperature, steel may suffer a pearlite to austenite phase transformation, changing its internal crystal structure from body-centered cubic to face-centered cubic. During this transformation, no significant elongation (Chen and Ye 2012) or contraction (Cooke 1988) is observed. The temperature ranges at which these changes occur are sensitive to the chemical composition of the steel, but are generally high, and often higher than the temperatures at which structural failure is reached (Cooke 1988).

As illustrated in Figure 6, at temperatures below the phase transformation in carbon steel: thermal strains grow nonlinearly with increasing temperature; heat capacity increases with increasing temperature; and, conductivity decreases with increasing temperature. As shown in Figure 6-a, it is common in some codified solutions (AISC 2010, AS 1998), to ignore the temperature dependence of the thermal expansion coefficient. This should be done with some care, as the thermal expansion coefficient governs the thermal strain field of structural members and (depending on the displacement boundary conditions) controls the magnitude and shape of thermal deformations.

Research needs include material testing to characterize the thermal conductivity, specific heat and thermal expansion coefficient of CFS at elevated temperatures, as well as the identification of critical temperatures at which phase transformation occur, and the thermal and mechanical properties of the material are modified.

\section{Cold-formed steel members at elevated temperatures}

The growing use of CFS in the construction industry has led to an increasing attention in the research community towards CFS performance under fire conditions. Thinwalled steel members are potentially more vulnerable to fire effects because of their high surface to volume ratio and relatively high thermal conductivity. If unprotected, these allow for rapid temperature increase, and consequently fast stiffness and strength degradation. Considering the temperature dependence of both mechanical and thermal properties, under realistic fire conditions, the stiffness, strength, and thermal elongation vary across the section of a member and along its length, creating a dynamically changing demand and capacity.

CFS members, as conventionally employed in light steel framing, are unique: efficient in terms of strength- 
a)

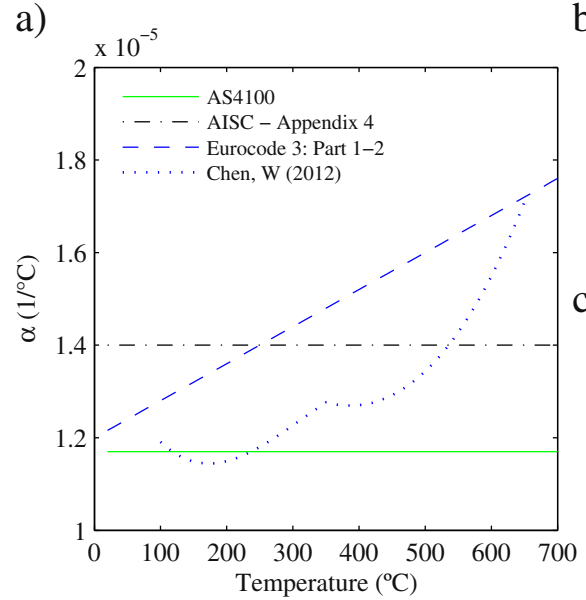

b)

c)
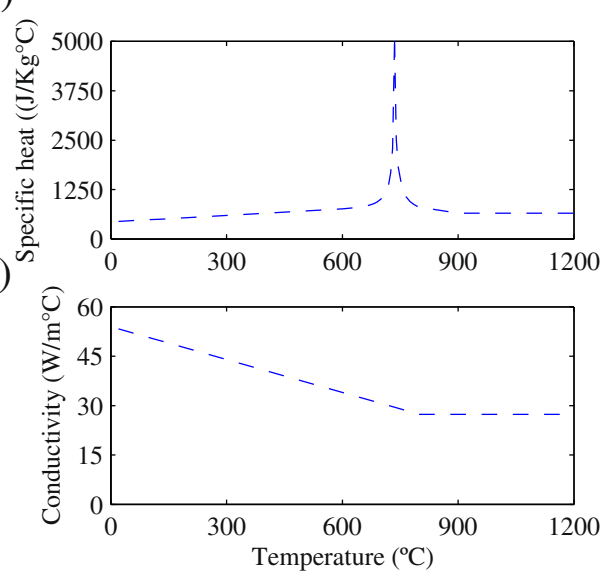

Figure 6 Thermal properties of steel at elevated temperatures (a) thermal expansion coefficient, (b) specific heat, and (c) thermal conductivity.

to-weight, but markedly more complex than typical hotrolled steel members due to their thin-walled nature and related cross-section stability modes that must be accounted for in design. Strength prediction of thinwalled CFS members relies either on the Effective Width Method (EWM) or the Direct Strength Method (DSM) to account for local and/or distortional buckling (see e.g., AISI 2012b). DSM is preferred because it directly integrates (computational) elastic buckling analysis into the design process. This was originally envisioned as a means to handle the wide variety of different shapes that can be formed from sheet steel (Schafer 2006), but can be modified to include the wide variety of different stiffness properties within a cross-section due to temperature gradients in the section.

Currently, the design of CFS members under fire is based on standard fire tests results, under controlled laboratory conditions. Fire resistance is judged based on the amount of time that a member or assembly can withstand elevated temperatures without exceeding specific failure criteria. This quantity is correlated with the amount of available time for occupant's evacuation and firefighter's operation before structural failure. To enable a more engineered solution, research studies are generally focused on predicting the load-carrying capacity of members at elevated temperatures, typically using modifications to existing design methods. This approach aims to use this strength prediction coupled with heat transfer analysis and a given fire demand to establish the building fire performance.

\section{Columns}

At ambient temperatures the capacity of a CFS column must consider the interaction of local, distortional, and global buckling as well as yielding. Under fire demand, all the buckling modes and yielding potentially become time and temperature dependent through the crosssection and along the length. In addition, due to thermal elongation and shift in the center of resistance from the changing mechanical properties, second-order $\mathrm{P}-\delta$ demands driven by thermal deformations can be important (Wang and Davies 2000).

At ambient temperature, certain modal interactions are generally considered (e.g., local-global) while others disregarded (e.g. local-distortional). Under thermal gradients these interactions can become far more complex (Batista-Abreu and Schafer 2013). For instance, experimental results qualitatively show that short columns with holes, dominated by local buckling at temperatures below $400^{\circ} \mathrm{C}$, fail in distortional buckling at higher temperatures (Feng et al. 2003b). Further, short columns without holes dominated by distortional mode at temperatures below $400^{\circ} \mathrm{C}$ exhibit local-distortional-global (flexural) interaction at higher temperatures (Feng et al. 2003b). These evolutions of modal interaction, as a function of temperature, can be quantified through modal identification methods using the constrained finite strip method as a basis (Li et al. 2012).

Experimental data shows that the axial capacity of columns is reduced with increasing temperatures (Feng et al. 2003b). For instance, short columns develop substantial axial strength degradation after $200^{\circ} \mathrm{C}$, withstanding about $15 \%$ of the failure load at ambient conditions at $700^{\circ} \mathrm{C}$.

Computational mechanical models of CFS columns at elevated temperatures typically utilize shell finite elements, are only loosely coupled to thermal analyses, and focus on the impact of a uniform, elevated temperature on the collapse capacity of a CFS column (Feng et al. 2003c; Kaitila 2002; Ranawaka and Mahendran 2006; Chen and Young 2006b; Ranawaka and Mahendran 2009b). The models use temperature dependent mechanical properties for $\mathrm{E}$ and $\mathrm{F}_{\mathrm{y}}$ typically based on testing conducted by the authors or 
on available retention factors (e.g., CEN 2005). Residual stresses are usually ignored (e.g. Ng and Gardner 2007) as they tend to diminish with increasing temperature (Ranawaka and Mahendran 2006; Lee 2004) and their influence on measured compressive ultimate load is negligible (Ranawaka and Mahendran 2010; Gardner and Nethercot 2004; Ellobody and Young 2005). In fact, this is consistent with findings at ambient temperatures as well (Schafer and Peköz 1998; Schafer et al. 2010).

Consistent with the thin-walled nature of the response, initial imperfections based on eigen- buckling modes are typically included in the models. At ambient temperatures significant progress has been made in realistic characterization of local, distortional, and global imperfections (Zeinoddini and Schafer 2012); however, at elevated temperatures simpler approaches are typically employed for imperfection magnitudes: local $\sim t$, distortional $\sim 2 \mathrm{t}$, global L/500, where $\mathrm{t}$ is the thickness and $\mathrm{L}$ the member length (Feng et al. 2004, Kaitila 2002; Ranawaka and Mahendran 2010). Under temperature gradients that are non-uniform through the cross-section, the necessity for fine-tuned imperfections is likely to be outweighed by the eccentricity in stiffness and the thermal bowing resulting from differential expansion (Feng and Wang 2005).

Work has also been completed on design methods for CFS columns at elevated temperatures. Under uniform temperature the DSM formulation (AISI 2012b Appendix 1) with updated $E(T)$ and related elastic buckling loads, and $\mathrm{F}_{\mathrm{y}}(\mathrm{T})$ and related squash load have been used within the traditional DSM expressions with good success (Heva et al. 2008; Ranawaka and Mahendran 2009b). Thermal bowing is more pronounced under non-uniform temperature, and Shahbazian and Wang (2011a, 2011b, 2012) have proposed modified DSM expressions and a new approach to determining the squash load capacity. The results are sensitive to the variation in the temperature across the section: temperature ratios between the exposed and unexposed flanges of 3.0, 2.0 and 1.5 at 120 minutes under a standard fire curve are utilized. Experimental data indicates actual temperature ratios are time dependent (see Figure 7) leading to further complications and a necessity to more directly couple the thermal and mechanical/design response. These temperature ratios were obtained through thermocouples located on the outside surface of the corners of lipped channels.

\section{Beams}

Compared to columns, CFS beams under elevated temperature have seen relatively little study. Many of the challenges for columns are similar for beams: timetemperature dependence, altered buckling modes, modal interactions, and material yielding. Numerical investigations, based on shell finite element models, include work

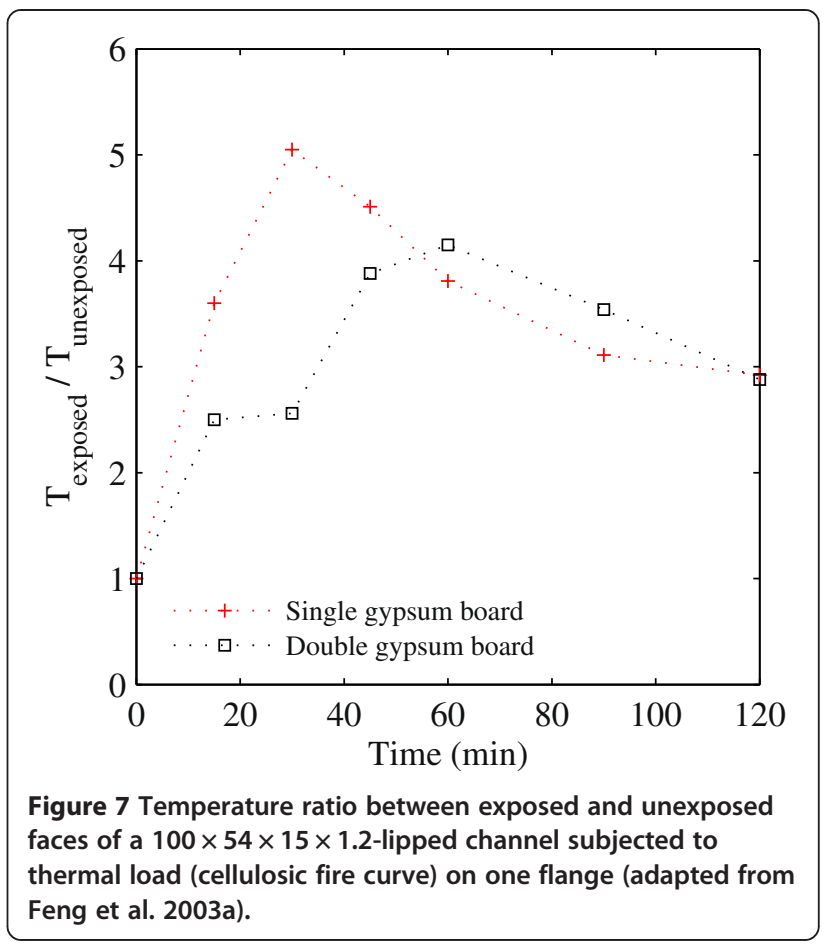

on lipped channels (Kankanamge and Mahendran 2008, 2012) and zee shapes (Lu et al. 2010). The models are subjected to uniform bending and analyzed with material properties consistent with uniformly elevated temperatures. Response is highly dependent on the end restraints, because they determine the development of compressive loads due to thermal elongation at initial stages of the fire action ( $\mathrm{Lu}$ et al. 2011a), and tensile forces due to catenary action during the fire response. Lateral restraint provided by sheathing is critical at ambient temperatures and under elevated temperatures. Prediction equations for lateraltorsional buckling of channel sections have been proposed (Kankanamge and Mahendran 2012), but experimental and further numerical studies are needed.

In summary, existing research needs include the determination of realistic temperature distributions throughout the length and cross-section of CFS members. The structural response dynamically evolves as the temperature field changes; therefore, the study of mode interactions is important to understand the behavior of thin-walled members at elevated temperatures. Besides strength and stiffness degradation, structural members incur thermal deformations that would eventually lead to failure. Hence, the study of semi-rigid end restraints is crucial. In terms of experimental data, very limited information is available on the behavior of single sections other than channels, and composite sections. Furthermore, design methods such as the Direct Strength Method and Effective Width Method have been validated for limited high temperature conditions; however this validation does not represent a sufficiently extensive range of possible scenarios. 
Cold-formed steel connections at elevated temperatures Connections are critical in understanding the performance of CFS structures under elevated temperatures. At ambient temperatures a significant body of literature exists on bolted steel-to-steel connections, with more limited studies on other fasteners and sheet steel connected to other materials (wood products, gypsum products, concrete, etc.). The knowledge base is similar, but with less depth of results, for connection performance at elevated temperatures.

Young and his colleagues have studied bolted steel-tosteel connections relevant to CFS construction at elevated temperatures, including proposed reduction factors (Lim and Young 2007), extensive (120 specimens) steady-state tests and analysis on single shear bolted connections (Yan and Young 2011a, Yan and Young 2012a), and complementary (62 specimen) transient-state tests (Yan and Young 2011b). The tests and analysis show the dominance of bearing failures as long as the " $3 \mathrm{~d}$ " edge distance criteria is maintained, and also show that the use of reduced mechanical properties at elevated temperatures, but traditional ambient temperature strength equations, provides an adequate prediction of strength. Results show the capacity of connections is significantly reduced with increasing temperature. For instance, experimental data shows a degradation of the bearing strength of bolted moment connections up to $90 \%$ at $700^{\circ} \mathrm{C}$, with respect to its capacity at ambient conditions.

Tests on screw fastened steel-to-steel connections in single shear under steady-state (Yan and Young 2012b) and transient-state (Yan and Young 2012c) conditions lead to similar findings as bolted connections. In addition, $\mathrm{Lu}$ et al. (2012) numerically studied shot-nailed and screwed connections, and again found that bearing failure of the thin steel sheet was the dominant failure mode. Design guidelines were provided to predict the capacity of shotnailed ( $\mathrm{Lu}$ et al. 2013), and screwed connections at elevated temperatures (Lu et al. 2011b).

In general, sheathed members are more stable and develop higher load-carrying capacity than unsheathed members. A methodology for sheathing-braced design of studs based on experimental data and discrete spring models is utilized at ambient conditions. However, studies on studto-sheathing connections at high temperatures are not currently found in the literature. Therefore, the feasibility of a similar methodology for fire design of CFS structures has not been judged. Research needs include the study of steel stud-to-sheathing connections at high temperatures. Additionally, the heat transfer through steel-to-steel and steel stud-to sheathing connections is relevant to understand the global behavior of CFS systems under fire.

Cold-formed steel assemblages at elevated temperatures While CFS material and member performance under elevated temperature represents important building blocks for understanding fire resistance, it is complete CFS assemblages (i.e. walls and floors) that provide structural support and resist fire demands. The standard approach for assessing walls and floors is the performance in a standard fire test, as discussed in detail below. Industry has performed such testing extensively for CFS framing assemblages (CFSEI 2012). From the standpoint of the development of performance-based design, these tests provide benchmarks that the development of analysis-based approaches may be compared with. Thus, understanding the standard fire test and response of CFS assemblages is an important step in understanding full fire response, but must be coupled with more advanced fire demand and heat transfer models to provide a complete prediction of response.

\section{Standard fire testing}

The Standard Test Methods for Fire Tests of Building Construction and Materials (ASTM 2012) are the most commonly referenced methods for fire testing of CFS assemblages. Equivalent, or similar, test standards also exist (UL 2003; ISO 1999). The fire curve used in ASTM was developed in 1918 (Manzello et al. 2008a), is equivalent to UL 263, and has a higher initial rate of temperature rise compared to the ISO 834 (ISO 1999) fire curve. Thus, for short test durations, the ASTM fire curve is more severe. However, fire curves have been strongly criticized due to the difference found between standard curves and fire curves measured in real compartment fires, both in terms of severity and duration. In this sense, the fire resistance specified for an assembly through standard testing may be different from the real response of the structure (Lane 2000). The worth of the standard test is more in its comparison to past practice, that in its absolute response.

A standard fire test is illustrated in Figure 8. The specimens (wall or floors) are subjected to a specific and prescriptive time-temperature curve (Figure 8-a). Thermocouples are strategically located on the specimens and they are monitored throughout the test (Figure 8-b and $c$ ). Fire resistance is defined by the time until "the maximum temperature increase on the unexposed side of the wall exceeds $181^{\circ} \mathrm{C}\left(325^{\circ} \mathrm{F}\right)$; the average temperature increase on the unexposed side of the wall exceeds $139^{\circ} \mathrm{C}$ $\left(250^{\circ} \mathrm{F}\right)$; a breach occurs in the wall that allows hot gases from the furnace to penetrate and ignite a cotton target on the unexposed side of the wall; or, the wall is unable to maintain its design load." (ASTM 2012). Test setup and response for typical tests are provided in Figure 8d-f for a wall and Figure 8g-i for a floor.

Criticisms of the standard fire test are well summarized by Grosshandler (2007): "The maximum size of the wall system is limited by the size of the furnace. The load conditions for the test specimen may not adequately mimic field use. The thermal environment of the furnace does 


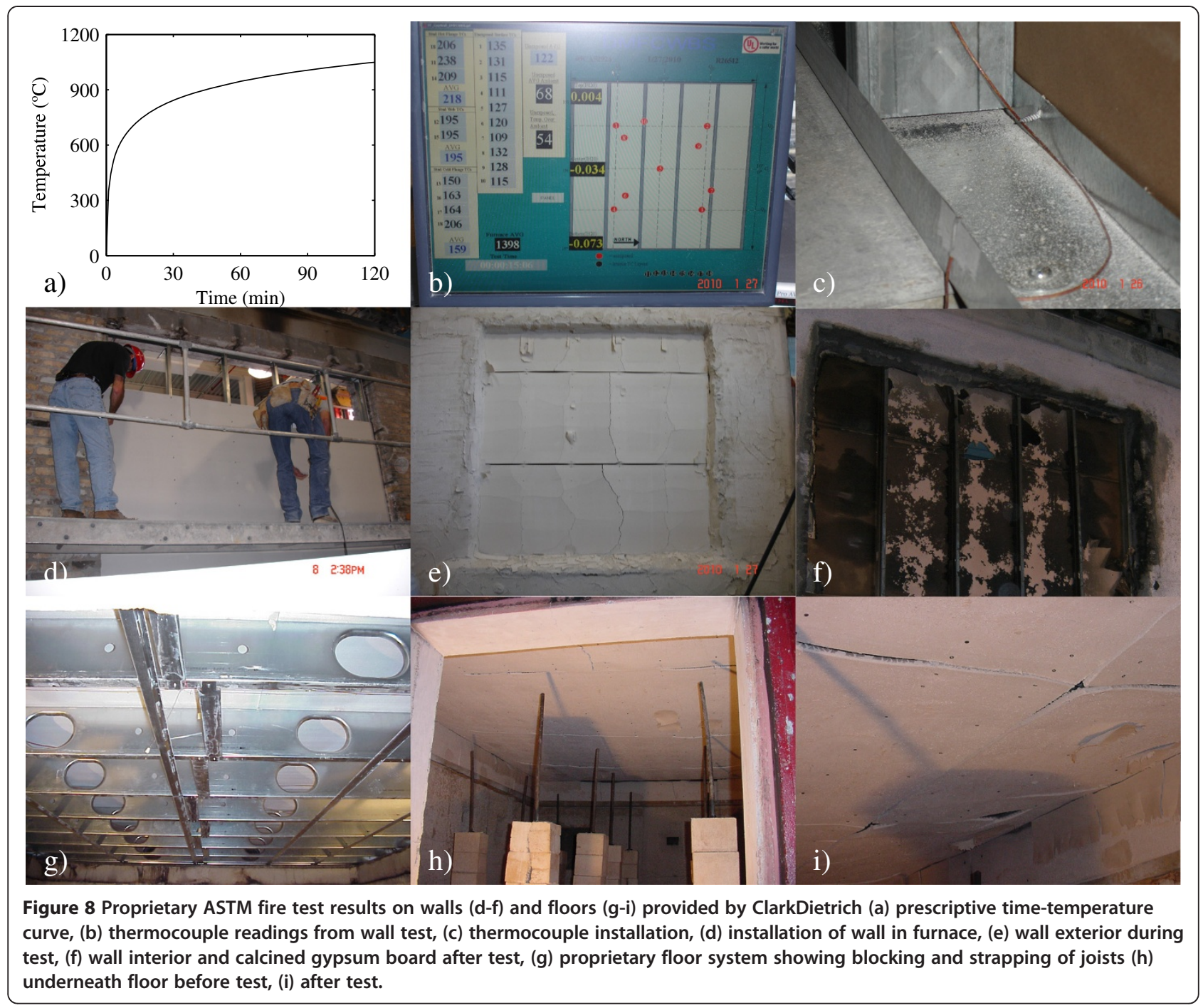

not mimic a real fire. The tests reveal no fundamental information about the performance of the specimen and provide little guidance on how to improve performance. The furnaces themselves are not standardized; hence, the same specimen could receive different ratings if tested in two different facilities. Ratings are based upon a single test, with no way to quantify the uncertainty or safety factor". In many ways the fact that "the tests reveal no fundamental information about the performance of the specimen" is the most damning and demonstrates how current practice provides no path towards significant improvement or change when driven by the standard fire test.

Even to use standard fire testing to advance basic modeling can be challenging since little, if any, of the specific data (thermocouple readings, deformations, etc.) is available in the public domain. Further, the pass/fail nature of the test has precluded studies focused on better understanding behavior. For example, the interaction between damage due to structural loads and degrading strength under realistic fire conditions has not been studied in detail.

By analyzing the data generated from standard fire tests, Ingberg (1928) developed a method to approximate the fire resistance time of a structure under a real fire, based on the fire resistance of a structure under standard fire conditions. This methodology compares the severities of real and standard fires, quantified as the areas under both fire curves. Other methods attempt to estimate "real" fire resistance rating based on the maximum temperatures that structural members develop. In general, these methodologies do not explicitly account for factors such as the type of combustible, geometry of the compartment, ventilation conditions, and heat release rate. Equations used to estimate the fire resistance rating are based on regression of limited experimental data related to tests with specific configurations and materials. 
Additionally, these methodologies do not consider the effect of loading conditions on the structural members, and the variation of temperature throughout the compartment.

\section{Performance of walls}

Performance of CFS walls in standard fire testing is summarized in CFSEI (2012). For both partition walls and for load bearing walls, the fire rating is largely a function of the thickness and number of gypsum (or similar) wallboards. Thus, the primary interest in research has been on the heat transfer aspects of the gypsum wallboard under the standard fire curve. The role of the fasteners as a thermal bridge, the role of the cross-section stiffness with respect to thermal bowing of the wall and local flange deformations, and the role of lost axial capacity due to decreased bracing stiffness from the wallboard as the board burns and undergoes calcination (or is saturated by a sprinkler) are important, but have seen little or no study.

The performance of the wallboard itself directly drives the thermal response and indirectly influences the mechanical response of the system. Wallboards consist of a pressed gypsum (and glass fiber) core, covered with thick sheets of paper. The sheets of paper maintain the integrity of the gypsum core even when it cracks, until they burn at about $200^{\circ} \mathrm{C}$ to $300^{\circ} \mathrm{C}$. Dehydration of gypsum plasterboards initiates at $100^{\circ} \mathrm{C}$ (Gerlich 1995; Ngu 2004), when water boils, leading to increased porosity and a considerable drop of thermal conductivity (Rahmanian 2011). For instance, calcination of the gypsum board is complete after 20 minutes at $400^{\circ} \mathrm{C}$, resulting in $\sim 20 \%$ density reduction and $\sim 80 \%$ loss of material strength (Cramer et al. 2003), as shown in Figure 9. Gypsum board damage depends on the maximum temperature reached and the rate of temperature increase and its relations to the moisture flow, ablation and cracking processes (Ariyanayagam and Mahendran 2012). Alternatives to gypsum wallboards such as bolivian magnesium and calcium silicate boards have shown better fire resistances (Chen et al. 2012), but are associated with increased cost.

Available data on thermo-mechanical properties of gypsum boards is commonly derived from research on lightweight wood construction. Thermal properties (i.e. specific heat, thermal conductivity, contraction and mass loss) of types $\mathrm{X}, \mathrm{C}, \mathrm{F}$ and $\mathrm{R}$ gypsum boards are available in the literature (Bakhtiary et al. 2000; Bénichou and Sultan 2005; Manzello et al. 2008a; Manzello et al. 2008b; Thomas 2002). Variability in the chemical composition and testing conditions (e.g. heating rate) of gypsum leads to scattered thermal properties results (Wakili and Hugi 2009). However, the chemical composition of the tested gypsum boards is not commonly stated in experimental reports. Modified thermal properties to implicitly account for mass transfer (e.g. water migration and re-condensation) and ablation
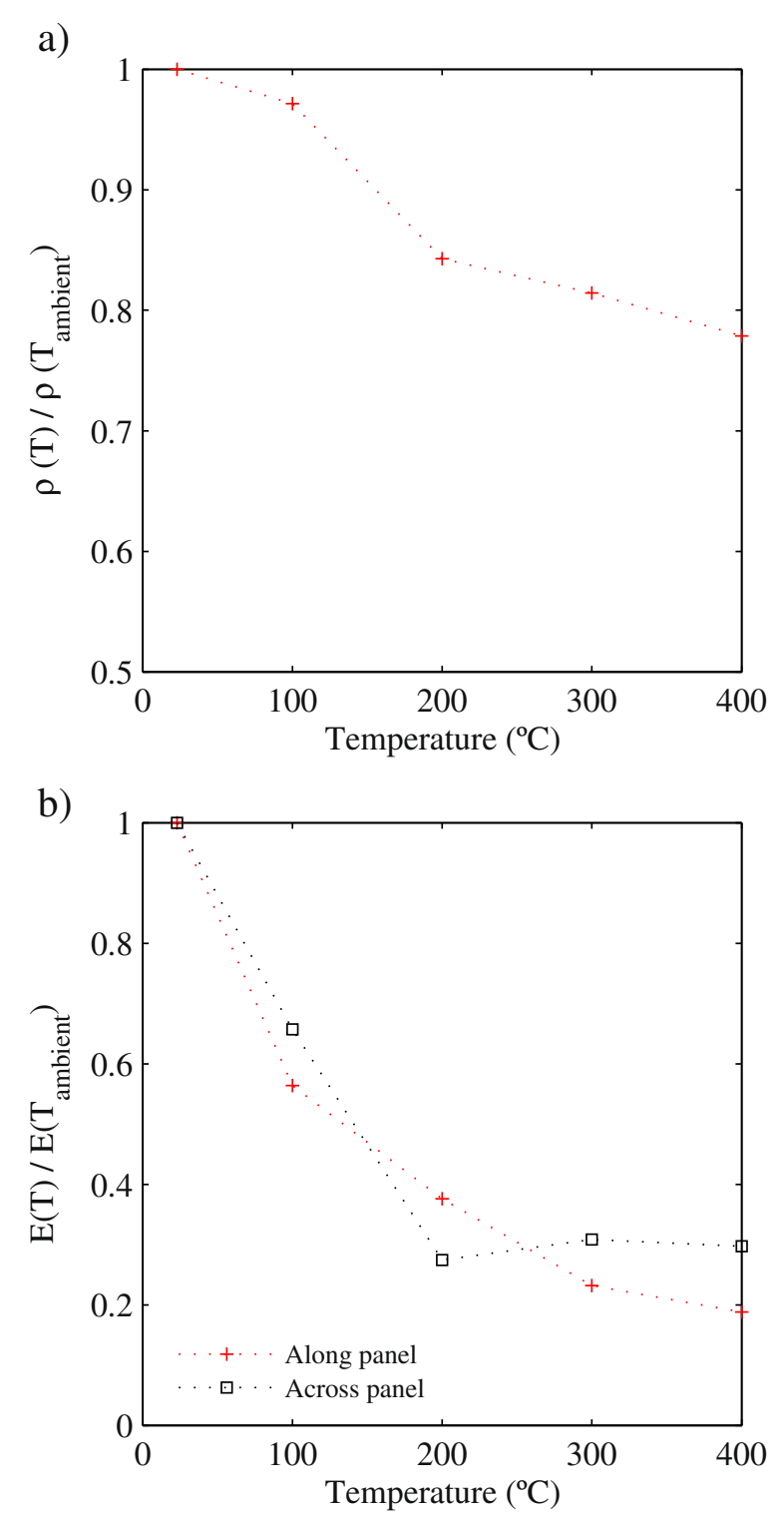

Figure 9 (a) Density and (b) elastic modulus retention of type $X$ gypsum board (adapted form Cramer et al. 2003).

process have also been proposed (Ang and Wang 2004; Rahmanian 2011).

Data on the mechanical properties of gypsum boards is scarce. Fuller (1990) showed the stiffness and strength of gypsum boards decays by $80 \%$ at $120^{\circ} \mathrm{C}$, after calcination. Similarly, Cramer et al. (2003) reported the variation of the elastic modulus, bending strength and thermal expansion coefficient along and across type $\mathrm{X}$ gypsum boards, up to $400^{\circ} \mathrm{C}$, after 60 minutes of fire exposure. Furthermore, Rahmanian (2011) reported the elastic modulus, bending and compressive strengths, and proposed linear stress-strain relations for standard and glass-fiber reinforced gypsum boards at elevated temperatures. 
CFS walls commonly contain cavity insulation for climate and sound control. In general, cavity insulation obstructs heat dissipation in the cavity, causing a faster temperature increase in the exposed face of the wall, while delaying the temperature increase in the unexposed face (Alfawakhiri and Sultan 2001). Whether or not this change in the heat transfer is beneficial or detrimental is an open question. Research indicates glass or cellulose fiber cavity insulation has little affect, but mineral fiber insulation generally increases fire resistance (Sultan and Lougheed 2002, Feng et al. 2003d). However, others conclude cavity insulation is generally detrimental to strength (Kolarkar 2010). Alternatives to cavity insulation have been explored by Mahendran and his colleagues, including glass and rock fiber external insulation and external insulation sandwiched between gypsum boards. Fire performance for these systems can be excellent (Kolarkar and Mahendran 2008, 2012; Gunalan and Mahendran 2010; Keerthan and Mahendran 2012, 2013).

\section{Performance of floors}

CFSEI (2012) summarizes available sources for prescriptive fire design of CFS floor systems; however, only limited information on the behavior of CFS floor-ceiling systems is available. Sultan et al. (1998) tested five floor specimens with CFS joists and gypsum board sheathing under standard fire conditions. It was observed that thermal bowing of the steel joists governs floor deflections until run-away occurs. In general, local buckling at the top flange of the joists near mid-span, and subsequent inelastic mechanism formation led to structural failure. Conclusions indicate that cavity insulation has a detrimental effect on the fire resistance of floor systems especially when the insulation melts, allowing the CFS joists to be completely exposed to fire after the gypsum falls off. The ability of the sheathing boards to remain in place governs the overall fire resistance of CFS floor assemblies (Alfawakhiri and Sultan 2001).

Baleshan and Mahendran (2010) tested three floorceiling systems looking at the advantages of using sandwiched insulation on the ceiling side of the CFS frame instead of cavity insulation. Results demonstrate that sandwiched insulation improves the fire resistance of floor systems by mitigating convective and radiative heat transfer from the external heat source to the CFS joists. It was observed that gypsum boards prevented lateral-torsional buckling of the joists during the tests. At high temperatures, local buckling along the CFS joist was prevalent, and pronounced crippling occurred near the supports.

The list of research needs related to CFS assemblages is exhaustive, as detailed in the previous sections. These needs begin with the characterization of fire demands based on realistic fire scenarios. Then, the actual heat transfer throughout the elements of the assemblage should be understood. The development of more accurate tridimensional and simplified heat transfer models is essential to enable coupled thermo-mechanical models useful for engineering-based analysis method. Furthermore, the study of the degradation of the capacity of the assemblage itself, and its interaction with the entire system is necessary for the development of a performancebased design method.

\section{The case for performance-based fire design of cold- formed steel systems}

Fire represents one of the most important hazards that building structures must be designed against. Most of the modern regulatory framework around building structures originated in response to the great fires of the late 19th and early 20th century. Today, this regulatory framework supports material standards that have adopted reliabilitybased design methods that largely bring other building hazards (snow, wind, conventional dead and live load) into a risk consistent framework. For complex hazards such as earthquakes the risk consistent methodology has been extended to cover multiple performance objectives, always insuring society's concern of minimizing life safety risk, but enabling and incentivizing engineers and building owners to consider higher levels of performance. This performance-based design approach is largely seen as the future, and provides the best potential for risk consistent multi-hazard design.

Fire resistance of buildings framed from CFS is guaranteed through prescriptive codes and the standardized test. While the level of safety has generally been found acceptable, the lack of an engineering/analysis-based approach to fire resistance of CFS structures impedes progress and stifles innovation, summarized here across four broad categories. First, the cost to industry, particularly for ASTM testing, is high and as a result little improvements are sought or found in even basic CFS wall and floor designs. Second, system-level mechanisms that provide enhanced resistance to fire through re-distribution of load are neither conceptualized, nor tested, nor designed in CFS structures due to lack of knowledge to complete such an approach and lack of financial reward for the engineer to do so. Third, risk consistent multi-hazard based design with fire is largely impossible since fire cannot be reasonably integrated with other hazards without a means to analyze the structure. Fourth, and finally, as multiple parties work to re-envision buildings to be greener and more sustainable, the current prescriptive approach to fire means fire protection is added as a constraint with a small set of known solutions instead of integrated within the larger optimization that needs to be performed.

Preliminary work on performance-based fire resistance has begun internationally, but it is still limited. Positive strides in this direction include codification of engineering/ 
analysis-based methods that predict the response of structures under fire demands such as those recently adopted for hot-rolled steel (AISC 2010). However, similar progress has not been made in this direction for CFS structures. CFS structures provide a compelling and challenging framework for advancing performance-based fire resistance. Compelling, because a significant percentage of the modern building stock uses CFS framed walls with gypsum board for interior fire resistance; when these same walls are load bearing, as in a highly efficient CFS framed building, additional considerations arise. Challenging, because the thin-walled nature of CFS members complicates conventional design significantly and at elevated temperatures the stability response is further modified and must be understood.

Significant challenges remain to developing a complete performance-based fire engineering solution for CFS structures; including: more realistic fire models; deeper understanding of the temperature dependence of CFS, gypsum, and connector thermal properties; three dimensional heat transfer models including gypsum board deterioration (dehydration, cracking, and ablation) processes; improved one-dimensional heat transfer models for design; better understanding of strength and stiffness degradation of CFS and connected wallboards at elevated temperatures, considering the influence of the test method, strain and heating rates and chemical composition; verified coupled thermo-mechanical models that accurately predict the response of CFS elements and subsystems; experimental research at large scale on CFS building structures, including fire development, cooling phase behavior and residual strength, and element and subsystems interactions; performance-based methods for CFS fire design; structural optimization of load-bearing and non-load-bearing fire protection systems; and multi-hazard building response and mitigation, including fire after earthquake and fire after blast.

\section{Conclusions}

Although work remains, the basic building blocks for analysis-based fire resistance of cold-formed steel (CFS) building assemblages and structures are in place and performance-based fire design for CFS structures can now be pursued. Prescriptive solutions under standard fire testing provide a variety of immediately available options for design, but are restricting innovation in CFS assemblages and systems and ultimately place fire outside of the riskconsistent framework that has been developed for other building natural hazards. Ideally, performance-based fire design brings the demand (fire modeling), propagation (heat transfer), and capacity (strength at elevated temperatures) all into the realm of analysis. This review article briefly summarizes current efforts in fire modeling and heat transfer. For capacity determination, the paper provides detailed reviews and composite data on the temperature dependence of sheet steels commonly used in CFS, members formed from CFS, and wall and floor assemblages framed from CFS. Available data is compared, along with existing codified provisions for other steels, and recommendations are provided for modeling and expected performance whenever possible. Codified provisions for analysis-based fire design of CFS will enable performance-based fire engineering of CFS structures and should be a near term goal. Work remains to provide detailed capacity predictions fully coupled with three-dimensional building models and simulated fires, but already this possibility exists for researchers, and in the future for designers as well.

\section{Competing interests}

The authors declare that they have no competing interests.

\section{Authors' contributions}

All listed authors made substantial intellectual contribution to this work; and read and approved the final manuscript.

\section{Acknowledgements}

The authors would like to thank ClarkDietrich for providing pictures taken during fire testing of wall and floor assemblages.

\section{Author details}

${ }^{1}$ Department of Civil Engineering, Johns Hopkins University, Baltimore, MD, USA. ${ }^{2}$ Department of Structural Engineering, University of Campinas, Campinas, Brazil. ${ }^{3}$ Structural Engineering Department, Cairo University University, Cairo, Egypt. ${ }^{4}$ Department of Civil Engineering, Johns Hopkins University, Baltimore, MD, USA.

Received: 6 March 2014 Accepted: 15 August 2014

Published: 29 August 2014

\section{References}

Alfawakhiri F (2001) Behaviour of cold-formed-steel-framed walls and floors in standard fire resistance tests. Carleton University, Ottawa, ON

Alfawakhiri F, Sultan MA (2001) Numerical modelling of steel members subjected to severe thermal loads. National Research Council Canada, Ottawa, ON

Allen D (2004) Designing Cold-Formed Steel Mid-Rise Structures: Innovations for Cost-Effective and Attractive Projects. Structure Magazine, Chicago, IL

AISC (2010) Specification for Structural Steel Buildings, Appendix 4: Structural Design for Fire Conditions. American Institute of Steel Construction, Chicago, IL

AISI (2012a) AISI S200-12: North American Standard for Cold-Formed Steel Framing General Provisions. American Iron and Steel Institute, Washington, DC

AISI (2012b) AISI S100-12: North American Standard for the Design of Cold-Formed Steel Structural Members. American Iron and Steel Institute, Washington, DC

ASTM (2012) ASTM E119-12a: Standard Methods of Fire Tests for Fire Tests of Building Construction and Materials. American Society for Testing and Materials, West Conshohocken, PA

ASCE (2009) Performance-Based Design of Structural Steel for Fire Conditions: A Calculation Methodology. American Society of Civil Engineers, Reston, VA

Ang CN, Wang YC (2004) The effect of water movement on specific heat of gypsum plasterboard in heat transfer analysis under natural fire exposure. Construction and Building Materials 18(7):505-515, http://dx.doi.org/10.1016/ j.conbuildmat.2004.04.003

Ariyanayagam AD, Mahendran M (2012) Fire Tests of Load Bearing Steel Stud Walls Exposed to Real Building Fires. Proceedings of the 7th International Conference on Structures in Fire. ETH Zürich, Zürich, Switzerland, pp 105-114, 6-8 June 2012

Bakhtiary SB, Jafarpoor F, Firoozyar F (2000) Thermal and mechanical properties of fire-resistant gypsum plasters. Asian J Civ Eng (Building and Housing) 1(2):67-82

Baleshan B, Mahendran M (2010) Full Scale Fire Tests of A New Light Gauge Steel Floor-Ceiling System, Proceedings of the 4th International Conference on Steel \& Composite Structures. Queensland University of Technology, Sydney, Australia, 21-23 July 2010 
Batista-Abreu JC, Schafer BW (2013) Stability Of Cold-Formed Steel Compression Members Under Thermal Gradients. Proceedings of the Annual Stability Conference Structural Stability Research Council. In: Missouri University of Science and Technology, Rolla, MO, pp 136-154, 17-19 April 2013

Bednarek Z, Kamocka R (2006) The heating rate impact on parameters characteristic of steel behaviour under fire conditions. J Civ Eng Manag 12(4):269-275, doi:10.1080/13923730.2006.9636403

Bénichou N, Sultan MA (2005) Thermal properties of lightweight-framed construction components at elevated temperatures. Fire and Materials 29(3):165-179, doi:10.1002/fam.880

CFSEl (2012) Technical Note on Cold-Formed Steel Construction, TECH-NOTE T100-12: Fire Rated Assemblies of Cold-Formed Steel Construction. Cold-Formed Steel Engineers Institute, Washington, DC

Chen W, Ye J (2012) Mechanical properties of G550 cold-formed steel under transient and steady state conditions. J Constructional Steel Res 73:1-11

Chen J, Young B (2006a) Corner properties of cold-formed steel sections at elevated temperatures. Thin-Walled Structures 44(2):216-223, doi:10.1016/j. tws.2006.01.004

Chen J, Young B (2006b) Design of cold-formed steel lipped channel columns at elevated temperatures, Proceedings of the International Colloquium on Stability and Ductility of Steel Structures. Instituto Superior Técnico, Lisbon, Portugal

Chen J, Young B (2007) Experimental investigation of cold-formed steel material at elevated temperatures. Thin-Walled Structures 45(1):96-110, doi:10.1016/j. tws.2006.11.003

Chen W, Ye J, Bai Y, Zhao X (2012) Full-scale fire experiments on load-bearing cold-formed steel walls lined with different panels. J Constructional Steel Res 79:242-254

Chen W, Ye J, Bai Y, Zhao X (2013) Thermal and mechanical modeling of load-bearing cold-formed steel wall systems in fire. J Structural Eng doi:10.1061/(ASCE)ST.1943$541 \times .0000862$

Clark CL (1953) High-temperature alloys. Pitman Metallurgy Series. Pitman Publishing Corporation, Toronto

Cooke GME (1988) An introduction to the mechanical properties of structural steel at elevated temperatures. Fire Safety J 13(1):45-54

Costes F (2004) Modélisation thermomécanique tridimensionnelle par éléments finis de la coulée continue d'aciers. Ecole Nationale Supérieure des Mines de Paris, Paris, France

Cramer SM, Friday OM, White RH, Sriprutkiat G (2003) Mechanical Properties Of Gypsum Board At Elevated Temperatures. In: Fire And Materials 2003: 8th International Conference. Interscience Communications Limited, San Francisco, CA, USA, pp 33-42

Ellobody E, Young B (2005) Structural performance of cold-formed high strength stainless steel columns. J Constructional Steel Res 61(12):1631-1649

CEN (2002) BS EN 1991-1-2:2002 Eurocode 1: Actions on Structures Part 1-2: General actions - Actions on structures exposed to fire. European Committee for Standardization, Brussels, Belgium

CEN (2005) BS EN 1993-1-2:2005 Eurocode 3: Design of Steel Structures. Part 1-2: General Rules - Structural Fire Design. European Committee for Standardization, Brussels, Belgium

Ewer J, Jia F, Grandison A, Galea E, Patel M (2008) SMARTFIRE V4.1: User Guide and Technical Manual - SMARTFIRE Tutorials. University of Greenwich, London, United Kingdom

Feng M, Wang YC (2005) An analysis of the structural behaviour of axially loaded full-scale cold-formed thin-walled steel structural panels tested under fire conditions. Thin-Walled Structures 43(2):291-332

Feng M, Wang YC, Davies JM (2003a) Axial strength of cold-formed thin-walled steel channels under non-uniform temperatures in fire. Fire Safety J 38(8):679-707, doi:10.1016/s0379-7112(03)00070-5

Feng M, Wang YC, Davies JM (2003b) Structural behaviour of cold-formed thin-walled short steel channel columns at elevated temperatures. Part 1: experiments. Thin-Walled Structures 41 (6):543-570, doi:10.1016/s0263-8231(03)00002-8

Feng M, Wang YC, Davies JM (2003c) Structural behaviour of cold-formed thinwalled short steel channel columns at elevated temperatures. Part 2: Design calculations and numerical analysis. Thin-Walled Structures 41(6):571-594, doi:10.1016/s0263-8231(03)00003-x

Feng M, Wang YC, Davies JM (2003d) Thermal performance of cold-formed thin-walled steel panel systems in fire. Fire Safety J 38(4):365-394, doi:10.1016/s0379-7112(02)00090-5

Feng M, Wang YC, Davies JM (2004) A numerical imperfection sensitivity study of cold-formed thin-walled tubular steel columns at uniform elevated temperatures. Thin-Walled Structures 42(4):533-555
Fuller JJ (1990) Predicting the Thermo-Mechanical Behavior of A Gypsum-ToWood Nailed Connection. Corvallis, OR, Oregon State University

Gardner L, Nethercot D, 2004 (2004) Numerical Modeling of Stainless Steel Structural Components-A Consistent Approach. J Structural Eng 130 (10):1586-1601, doi:10.1061/(ASCE)0733-9445(2004)130:10(1586)

Gerlich JT (1995) Design of Loadbearing Light Steel Frame Walls for Fire Resistance. vol Fire Engineering Research Report 95/3. School of Engineering, University of Canterbury, Christchurch, New Zealand

Grosshandler WL (2007) Fire Resistance Proficiency Testing of Gypsum/Steel-Stud Wall Assemblies, Technical Memorandum of PWRI 4075, Wind and Seismic Effects, U.S./Japan Natural Resources Development Program (UJNR), Joint Meeting, 39th. Public Works Research Institute, Tsukuba, Japan, pp 334-344, 14-16 May 2007

Gunalan S, Mahendran M (2010) Structural and Fire Behaviour of a New Light Gauge Steel Wall System, Proceedings of the 6th International Conference on Structures in Fire. DEStech Publications, Inc, Lancaster, PA, pp 43-50, 2-4 June 2010

Heva B, Yasintha D, Mahendran M (2008) Local Buckling Tests of Cold-formed Steel Compression Members at Elevated Temperatures. Proceedings of the Paper presented at the 5th International Conference on Thin-walled Structures - ICTWS. Innovations in Thin-walled Structures, Gold Coast, Australia

IBC (2012) International Building Code Chapter 6: Types of Construction. International Code Council, Country Club Hills, IL

ISO (1999) ISO 834-1:1999: Fire Resistance Tests - Elements of Building Construction. International Organization for Standardization, Geneva, Switzerland

Kaitila O (2002) Finite element modelling of cold-formed steel members at high temperatures. Helsinki University of Technology, Espoo, Finland

Kankanamge ND, Mahendran M (2008) Numerical Studies Of Cold-Formed Steel Beams Subject To Lateral-Torsional Torsional Buckling At Elevated Temperatures, Proceedings of the 5th International Conference on Thin-Walled Structures. Queensland University of Technology, Brisbane, Australia

Kankanamge ND, Mahendran M (2011) Mechanical properties of cold-formed steels at elevated temperatures. Thin-Walled Structures 49(1):26-44, doi:10.1016/j.tws.2010.08.004

Kankanamge ND, Mahendran M (2012) Behaviour and design of cold-formed steel beams subject to lateral-torsional buckling at elevated temperatures. Thin-Walled Structures 61:213-228

Karren KW (1970) Corner Properties Of Cold-Formed Steel Structural Members. Effects of Cold Work In Cold-Formed Steel Structural Members, vol 70-1. Cornell Engineering Research Bulletin, Ithaca, NY

Keerthan P, Mahendran M (2012) Numerical Modelling of Load Bearing LSF Walls Under Fire Conditions, Proceedings of the 7th International Conference on Structures in Fire. ETH Zürich, Zürich, Switzerland, pp 205-214, 6-8 June 2012

Keerthan P, Mahendran M (2013) Thermal performance of composite panels under fire conditions using numerical studies: plasterboards, rockwool, glass fibre and cellulose insulations. Fire Technol 49(2):329-356, doi:10.1007/ s10694-012-0269-6

Kodur V, Dwaikat M, Fike R (2010) High-temperature properties of steel for fire resistance modeling of structures. J Mater Civ Eng 22(5):423-434, doi:10.1061/(asce)mt.1943-5533.0000041

Kolarkar PN (2010) Structural and Thermal Performance of Cold-formed Steel Stud Wall Systems under Fire Conditions. Queensland University of Technology, Brisbane, Australia

Kolarkar P, Mahendran M (2008) Thermal Performance of Plasterboard Lined Steel Stud Walls, Proceedings of the 19th International Specialty Conference on Cold-Formed Steel Structures. Missouri University of Science and Technology, Rolla, MO

Kolarkar P, Mahendran M (2012) Experimental studies of non-load bearing steel wall systems under fire conditions. Fire Safety J 53:85-104

Lane B (2000) Performance-Based Design for Fire Resistance, Modern Steel Construction. American Institute of Steel Construction, Chicago, IL

Lee JH (2004) Local buckling behaviour and design of cold-formed steel compression members at elevated temperatures. Queensland University of Technology, Brisbane, Australia

Lee JH, Mahendran M, Makelainen P (2003) Prediction of mechanical properties of light gauge steels at elevated temperatures. J Constructional Steel Res 59(12):1517-1532, doi:10.1016/s0143-974x(03)00087-7

Li Z, Batista Abreu JC, Adany S, Schafer BW (2012) Cold-formed steel member stability and the constrained finite strip method. Proceedings of the 6th International Conference on Coupled Instabilities in Metal Structures. CIMS, Glasgow, United Kingdom 
Lim JBP, Young B (2007) Effects of elevated temperatures on bolted momentconnections between cold-formed steel members. Eng Struct 29(10):2419-2427

Lu W, Makelainen P, Outinen J (2010) Numerical investigation of cold-formed steel purlin in fire. Journal of Structural Mechanics 43(1):12-24

Lu W, Makelainen P, Outinen J (2011a) Behaviour of Cold-Formed Z-Shaped Steel Purlin in Fire. Proceedings of Paper presented at the Civil Engineering '11 - 3rd International Scientific Conference. Jelgava, Latvia

Lu W, Mäkeläinen P, Outinen J, Ma Z (2011b) Design of screwed steel sheeting connection at ambient and elevated temperatures. Thin-Walled Structures 49(12):1526-1533

Lu W, Ma Z, Mäkeläinen P, Outinen J (2012) Behaviour of shear connectors in cold-formed steel sheeting at ambient and elevated temperatures. Thin-Walled Structures 61:229-238

Lu W, Ma Z, Mäkeläinen P, Outinen J (2013) Design of shot nailed steel sheeting connection at ambient and elevated temperatures. Eng Struct 49:963-972

Mäkeläinen P, Outinen J (1998) Mechanical properties of an austenitic stainless steel at elevated temperatures. J Constructional Steel Res 46(1-3):455

Manzello SL, Grosshandler WL, Mizukami T (2008a) Furnace Testing of Full-Scale Gypsum Steel Stud Non-Load Bearing Wall Assemblies: Results of Multi-Laboratory Testing in Canada, Japan and USA, Proceedings of the 5th International Conference on Structures in Fire. Research Publishing Services, Singapore

Manzello SL, Park SH, Mizukami T, Bentz DP (2008b) Measurement Of Thermal Properties Of Gypsum Board At Elevated Temperatures. Proceedings of the 5th International Conference on Structures in Fire. Nanyang Technological University, Singapore, 28-30 May, 2008

McGrattan KB, Floyd JE, Hostikka S, Prasad KR (2002) Fire Dynamics Simulator (Version 3): Users Guide. NISTIR 6784, 2002 Ed. U.S. Department of Commerce. In: National Institute of Standards and Technology, Gaithersburg, MD

Ng KT, Gardner L (2007) Buckling of stainless steel columns and beams in fire. Eng Struct 29(5):717-730

Ngu CN (2004) Calcination of Gypsum Plasterboard under Fire Exposure. Fire Engineering Research Report 04/6. Department of Civil Engineering, University of Canterbury, Christchurch, New Zealand

Outinen J (2006) Mechanical Properties of Structural Steel at High Temperatures and after Cooling Down, Doctoral Dissertation. Helsinki University of Technology, Espoo, Finland

Outinen J, Mäkeläinen P (1999) Mechanical Properties of an Austenitic Stainless Steel at Elevated Temperatures. In: Chan SL, Teng JG (eds) Advances in Stee Structures (ICASS '99). Elsevier, Oxford, pp 1063-1069, doi:10.1016/b978008043015-7/50124- $x$

Outinen J, Mäkeläinen P (2004) Mechanical properties of structural steel at elevated temperatures and after cooling down. Fire Mater 28(2-4):237-251

Quintiere JG (1989) Fundamentals of Enclosure Fire "Zone" Models. J Fire Protect Eng 1(3):99-119

Rahmanian I (2011) Thermal And Mechanical Properties of Gypsum Boards And Their Influence on Fire Resistance Of Gypsum Board Based Systems. University of Manchester, Manchester, England

Ramberg W, Osgood WR (1943) Description of Stress-Strain Curves By Three Parameters. Technical Notes. National Advisory Committee for Aeronautics, Washington, DC

Ranawaka T, Mahendran M (2006) Finite element analyses of cold-formed steel columns subject to distortional buckling under simulated fire conditions, Proceedings of the International Colloquium on Stability and Ductility of Steel Structures. Instituto Superior Técnico, Lisbon, Portugal, pp 747-755

Ranawaka T, Mahendran M (2009a) Experimental study of the mechanical properties of light gauge cold-formed steels at elevated temperatures. Fire Safety J 44(2):219-229, doi:10.1016/j.firesaf.2008.06.006

Ranawaka T, Mahendran M (2009b) Distortional buckling tests of cold-formed steel compression members at elevated temperatures. J Construct Steel Res 65(2):249-259, doi:10.1016/j.jcsr.2008.09.002

Ranawaka T, Mahendran M (2010) Numerical modelling of light gauge cold-formed steel compression members subjected to distortional buckling at elevated temperatures. Thin-Walled Structures 48(4-5):334-344, doi:10.1016/j.tws.2009.11.004

Rasmussen KJR (2003) Full-range stress-strain curves for stainless steel alloys. J Construct Steel Res 59(1):47-61, http//dx.doi.org/10.1016/50143-974X(02)00018-4

Rubini P (2006) Simulation of Fires in Enclosure (SOFIE). Cranfield University, Bedfordshire, United Kingdom

Santos P, Martins C, da Silva LS, Bragança L (2013) Thermal performance of lightweight steel framed wall: The importance of flanking thermal losses. J Build Phys doi:10.1177/1744259113499212
Schafer BW (2006) Review: The Direct Strength Method of Cold-Formed Steel Member Design. Proceedings of the Stability and Ductility of Steel Structures. Instituto Superior Técnico, Lisbon, Portugal

Schafer BW (2011) Cold-formed steel structures around the world: A review of recent advances in applications, analysis and design. ECCS, Steel Construct 4(3):141-149, doi:10.1002/stco.201110019

Schafer BW, Peköz T (1998) Computational modeling of cold-formed steel: characterizing geometric imperfections and residual stresses. J Construct Steel Res 47(3):193-210

Schafer BW, Li Z, Moen CD (2010) Computational modeling of cold-formed steel. Thin-Walled Structures 48(10-11):752-762, http://dx.doi.org/10.1016/S0143974X(02)00018-4

SCI (1993) Building Design using Cold Formed Steel Sections: Fire Protection. British Library Cataloguing-in-Publication Data, Silwood Park, Ascot

Shahbazian A, Wang YC (2011a) Application of the Direct Strength Method to local buckling resistance of thin-walled steel members with non-uniform elevated temperatures under axial compression. Thin-Walled Structures 49(12):1573-1583

Shahbazian A, Wang YC (2011 b) Calculating the global buckling resistance of thin-walled steel members with uniform and non-uniform elevated temperatures under axial compression. Thin-Walled Structures 49(11):1415-1428, doi:10.1016/j. tws.2011.07.001

Shahbazian A, Wang YC (2012) Direct Strength Method for calculating distortional buckling capacity of cold-formed thin-walled steel columns with uniform and non-uniform elevated temperatures. Thin-Walled Structures 53:188-199

Shahbazian A, Wang YC (2013) A simplified approach for calculating temperatures in axially loaded cold-formed thin-walled steel studs in wall panel assemblies exposed to fire from one side. Thin-Walled Structures 64:60-72

Spalding B (1978) PHOENICS. Concentration Heat And Momentum Limited, London,UK

AS (1998) AS 4100-1998: Steel Structures. Standards Australia Limited, Sydney, Australia

Sultan M (1996) A model for predicting heat transfer through noninsulated unloaded steel-stud gypsum board wall assemblies exposed to fire. Fire Technol 32(3):239-259, doi:10.1007/bf01040217

Sultan MA, Lougheed GD (2002) Results of Fire Resistance Tests on Full-Scale Gypsum Board Wall Assemblies. Internal Report, Institute for Research in Construction, vol 833. National Research Council Canada, Ottawa, ON

Sultan MA, Séguin YP, Leroux P (1998) Results of fire resistance tests on full-scale floor assemblies, IRC-IR-764. National Research Council Canada, Ottawa, ON

Thomas G (2002) Thermal properties of gypsum plasterboard at high temperatures. Fire Mater 26:37-45, doi:10.1002/fam.786

UL (2003) UL 263: Standard for Safety for Fire Tests of Building Construction and Materials. Underwriters Laboratories Inc, Northbrook, IL

Uribe J (1969) Aspects of The Effects of Cold-Forming on The Properties And Performance of Light-Gage Structural Members, vol Report No. 333. Department of Structural Engineering, Cornell University, Ithaca, NY

Wakili KG, Hugi E (2009) Four types of gypsum plaster boards and their thermophysical properties under fire condition. J Fire Sci 27(1):27-43, do: $10.1177 / 0734904108094514$

Wang YC, Davies JM (2000) Design of thin-walled steel channel columns in fire using Eurocode 3 Part 1.3. Proceedings of the 1st International Workshop on Structures in Fire, Copenhagen, Denmark, pp 181-193, 19-20 June 2000

Yan S, Young B (2011a) Tests of single shear bolted connections of thin sheet steels at elevated temperatures_-Part I: Steady state tests. Thin-Walled Structures 49(10):1320-1333

Yan S, Young B (2011b) Tests of single shear bolted connections of thin sheet steels at elevated temperatures-Part II: Transient state tests. Thin-Walled Structures 49(10):1334-1340

Yan S, Young B (2012a) Bearing factors for single shear bolted connections of thin sheet steels at elevated temperatures. Thin-Walled Structures 52:126-142

Yan S, Young B (2012b) Screwed connections of thin sheet steels at elevated temperatures - Part I: Steady state tests. Engineering Structures 35:234-243

Yan S, Young B (2012c) Screwed connections of thin sheet steels at elevated temperatures - Part II: Transient state tests. Engineering Structures 35:228-233

Zeinoddini VM, Schafer BW (2012) Simulation of geometric imperfections in cold-formed steel members using spectral representation approach. Thin-Walled Structures 60:105-117

\section{doi:10.1186/s40038-014-0001-3}

Cite this article as: Batista Abreu et al:: Review: development of performance-based fire design for cold-formed steel. Fire Science Reviews 2014 3:1. 